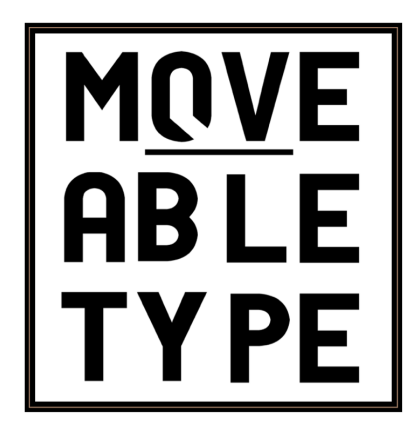

Re-viewing and Reparations in Olivia Laing's Funny Weather.

Author: Sarah Chambré

Source: Moveable Type, Vol.13, 'Ambience' (2021)

DOI: $10.14324 / 111.1755-4527.114$

MoveableType is a Graduate, Peer-Reviewed Journal based in the Department of English at UCL.

(C) 2021 Sarah Chambré. This is an Open Access article distributed under the terms of the Creative Commons Attribution License (CC-BY) 4.ohttps://creativecommons.org/licenses/by/4.0/, which permits unrestricted use, distribution, and reproduction in any medium, provided the original author and source are credited. 


\title{
Re-viewing and Reparations in Olivia Laing's Funny Weather
}

\author{
Sarah Chambré
}

Funny Weather: Art in an Emergency. By Olivia Laing. 2020. 368p. Picador. ISBN 9781529027648.

Olivia Laing assembles a decade's worth of her writing about art and culture in this rich collection of essays which are loosely grouped by category with little chronological constraint. Her own artistic curation creates a temporal doubling, a dialogue between and within essays, and a meta commentary on political, environmental, social and cultural emergencies. Composed on both sides of the Atlantic during the austerity decade 2011-2020, her work addresses these issues and their interrelated resonance over the long twentieth century. Reading these pieces in conversation with each other unmoors them from their initial publication contexts to create a larger, entangled embodiment of actors, canvases and environment in the broadest sense of these terms. In this sweeping cultural interrogation of the period, Laing complicates her evaluations by engaging in paranoid yet reparative readings in homage to Eve Kosofsky Sedgwick. By 'gathering information' and 'tracing links', Laing allows the minoritised and excluded to speak through original acts of creation and expression and, through her animated entangled (re)creation, addresses the swelling forces of late capitalism. ${ }^{1}$

The concept of biography is implicitly probed by Laing's style and mixed register. Her viewpoint constantly shifts from large to small, from the deeply personal to reflections on conceptual flowering, collaborative groupings, and collective action. Each artist is situated and connected within their time and community whilst speaking through and across these placements. The first nine essays, collected under the title 'Artists' Lives', represent an

\footnotetext{
${ }^{1}$ Olivia Laing, Funny Weather: Art in an Emergency (London: Picador, 2020), pp. 2-3. Subsequent quotations will be cited parenthetically in the text.
} 
eclectic range of artistic styles linked by their rejection of the mainstream. Characterised by contextual biography, these essays effortlessly interweave the artists' life stories with descriptions of their socio-political environments, artistic networks, and descriptions of individual works. 'Four Women' offers us a perspective of feminine counterculture comprising an admiring and affectionate vignette of how women artists see things differently. The penultimate section entitled 'Love Letters' offers an intimate personal reflection of artists who shaped and nourished Laing's own artistic development. In a sense, all the pieces are love letters to their subjects. There is a fresh perspective in each one but the structural divisions sharpen our reading, alert us to their own artificiality, and extend Laing's multivalenced style. Her essays move from biography to commentary, dwell tenderly on feminist paeans and develop theoretical frames, retaining throughout a personal affirmation. Laing's voice, never absent, changes from being coolly and sharply observant in the early essays to passionate and outraged in the later ones. It should be no surprise that she ends the collection with a recorded conversation, revealing her open, frank, and strongly held beliefs. No artifice, no veil and an open discourse.

Her portrayal of David Hockney is characteristically prismatic. It shifts registers through segments of biography, personal portrait, and demonstrates how his artistic style is both embedded in his era and yet breaks free to create a strikingly new vision. His 'central question was how to depict bodies in space while capturing something of the relationship, the currents of emotion between them' (35). This is one of many moments at which Laing not only penetrates the critical essence of her subjects and their style but also reveals her own stylistic methodology. For her, the Jamesian description '[c]aught in the act' describes Bacon's 'aptitude and delight in arresting flesh in motion, sliding and sliming between positions'(179). This is Laing's own gift - she catches her subjects enacting their moment, reacting and reflecting the era in which they find themselves to frame a new way of representation and perception, offering resistance and hope. 'Caught in the act' has a more sinister inference in Hockney's articulation of emergent British queer culture and his ignition of the West Coast scene. Themes of queer repression, expression and self-fashioning are 
recapitulated and extended in her central piece on 'Queer British Art' and resonate in other pieces. Laing weaves a thoughtful queer narrative throughout her collection with AIDs as a dark vector of death and loss. Close readings of individual paintings, clean stylish and spare, intersperse these segments of biography and stylistic development. With the air of an ambient gallery visit with a highly knowledgeable and sympathetic curator, Laing ventriloquises Hockney to depict a shift in his style and directly address the reader, as she does on many occasions: 'you have a fixed point, you have no movement; in short you are not there really' (36).

All her readings are queer, slantwise slices of life and art, expressive of alternative viewpoints. This shifting, fluid style avoids fixed vantage points and temporal or spatial anchoring. Laing telescopes in and out, offering close readings of artworks, interweaving biographical glimpses and socio-political morsels. In a single paragraph, she shifts from detailed observation to metaphysical and philosophical interpretations. The opening piece 'A spell to Repel Ghosts: Jean-Michel Basquiat' is a fine example. Within the space of four pages, Laing provides a breath-taking kaleidoscopic tour of the artist's origin myths for the cognoscenti artworld. Basquiat is discussed as a 'wild and inscrutable' child 'genius' (11) from a 'privileged' background who was nurtured by his art-loving mother. He was later injured in a car-accident which, combined with his family breakdown, was a foundational rupturing experience that perhaps contributed to his style as a graffiti artist and word and object scavenger. Finally, with his entry onto the New York scene he was 'flipped from hungry outsider to hot property'. With a light touch and technical finesse, Laing identifies the essential elements of Basquiat's work in a few words: 'worldly, reticent, communicative, crude and expert all at once'(14). Her linguistic strokes are unadorned, cool, and spare, offering glimpses before swiftly shifting subject and orientation. They combine to give us an intimate picture of the young artist as well as his self-aware, raw engagement with race in the art world. Laing presents his work as an active protest and insightful reworking of American history and its white foundational myth. Ironically, the very agents it satirised and critiqued would later come to value it with little self-consciousness, an outcome Basquiat both 
anticipated and deplored. The dispersed commercial afterlife of his work neuters his intent but fulfils his ambition 'to colour every surface with his runes' (19). Laing is ever present as a mediator of Basquiat's emergence and work but also acts as a gentle, seemingly impartial guide, drawing readers in and leaving them to connect and engage.

She creates her own networks by juxtaposing artists, offering us a realist picture of them while also providing glimpses of other artists, events, genres and eras which refract and provide implicit commentary in addition to her own meditations and sympathetic reflections. Despite the potential for despair in these themes, she distils and delights in the 'nourishment' offered by acts of creativity and rebellion (4). The voices and artistic acts of her subject shine through and are given space by her curation and commentary. Intriguingly entangled, these voices and stories mix with Laing's own reflection and lived experience. Her tonal shifts occur effortlessly and colour a variegated palette. She excels at capturing the vividness and accessibility Ben Highmore demands of the finest cultural appraisal: blending 'intellectual, political and moral seriousness with lightness of ...presentation'. ${ }^{2}$ For him, critical language should become more attuned to its objects: considering 'size, shape, angle, breadth, connection, attitude, tone'(244). Constructed in the mixed registers that Laing employs with 'deliberate jumps in perspective and shifts in tone', these perspectives create for the reader 'the capacity to connect to them, to recognize them, and to respond to them ... by echoing their modes of attention'(243). Laing is certainly attuned to her subjects, comprehensively considering their aesthetic orientation, and, by placing them in their personal story, their world, and her own, she creates just these echoes.

The polyphonic, stereoscopic, dialogic quality of these essays exemplifies Felski's application of Latourian Actor-Network Theory. It is this paradigm that for Michael Marcinkowski, a poet and technologist interested in human-computer interaction, corresponds to ambient literature because Felski mimics the kinds of issues that have propelled [its] present development'. Marcinkowski stakes a wider claim for ambient

\footnotetext{
${ }^{2}$ Ben Highmore, 'Aesthetic Matters: Writing and Cultural Studies', Cultural Studies, 32.2 (2018). pp.243-4.
} 
literature beyond its emergent digital forms which make explicit the 'conscious engagement of both the sociological conditions of their reception and the feedback loop by the presence of the reader'. ${ }^{3}$ This miniaturises the wider processes by which a cultural form is uniquely defined by its socio-historical moment, accumulates cultural history, and is interpreted in a complex embodied enactment. For Felski, it is this connectedness and these entanglements that are 'forged and sustained by drawing on the distinctive appeal of an artwork'. ${ }^{4}$ Laing constructs and performs these complex intricacies to engage the reader within and between her essays in complex systems and feedback loops that create and sustain the artwork and artist in a fluid socio-cultural environment. She takes her readers on a metaphysical cultural tour of the twentieth century. Firmly grounding her works in a specific moment and location with detailed reference to artist biography and to wider socio-cultural frameworks, her subjects simultaneously float free creating a larger temporal and spatial framework. In this, she interweaves her own voice both recollecting the subject in its own time, providing a present commentary, and trawling a personal and collective enduring past. Triangulating a tender intimacy between her subject, their oeuvre, and her reader, she offers a tone at once serious and effervescently playful. She quite literally takes her reader with her on a journey that is contextually anchored and yet, in her Felskian disregard for the constraints of periodicity, contextually divergent by allowing her subjects to speak to one another in timeless universalities. Her frieze column 'Between the Acts' references Virginia Woolf pulling off the same magic in her 1940 novel of the same title with her juxtaposition of present and threatening future in the shadow of deep time. Laing amplifies, connects and brackets her reading of this novel with her own reflection of a walk and another (opera) performance in which Tillman's set design concertinas acts of European violence. The sense of looming disquiet does not need to be spelt out.

Felskian networks permeate and trace the collection. The importance of the collective, collaboration, and friendships is striking in the first set. Andy Warhol, whilst not

\footnotetext{
${ }^{3}$ Michael Marcinkowski, 'Context Stinks'. Ambient Literature. https://research.ambientlit.com/index.php/2018/02/27/context-stinks/ accessed 20.4.21

${ }^{4}$ Rita Felski. “'Context Stinks!”. New Literary History, vol. 42. No. 4, 2011. p.584.
} 
given a full biography, has his Witney show featured in a frieze column but stalks the pages as a recurring presence in his influence, care, and friendship for other artists. This interconnected and influential presence is perhaps reflected in his position with the largest number of human entries in the index. Felski proposes a phenomenological framework in Hooked (2020), her ground-breaking renewal of reception studies centring on network theory with its insistence on the agency of both human and non-human actors. ${ }^{5}$ These abound in Laing's collection with equal weight to the latter. The index highlights these: Aids, blood, bodies, Brexit, clubs, dancing, freedom, gardening, gay lives, love, power, reality, resistance, utopia and violence accumulate frequent entries through the pieces. The highest entry is 'sex' with Laing's wry humour in evidence with a separate entry for 'not having', matched by an earlier entry categorised as 'bodies, licking of' $(351,340)$. The agency of the artworks as actors is often engendered by active language. Agnes Martin's works are typical in this respect: 'They aren't meant to be read, but rather responded to' (24).

'Making space' is a persistent concept which co-opts repeating ideas of fertility and coexistence, merging and nudging us towards the dynamic central theme of hospitality. Derek Jarman, one of Laing's 'holy trinity' alongside Freddie Mercury and David Bowie (308), coaxing his garden into abundance from a wasteland, creates from this, like many of her artists, beauty and promise - 'cooking up something out of practically nothing' (94). Laing's overt pieces of autobiography address her own gardening passion and her 'feral' period, a lived consideration of how we share our planet. Like many of the notions in this book, these permeate insistently from artwork to world view. Many of the artworks considered propose a generous, expansive orientation (Martin, Rauschenberg) - it is for the viewer to decide how to enter or participate in these open spaces; assemblages of found objects (Cornell, Rauschenberg's 'secret language of junk' (53)) and create new space for the discarded. Landscape offers a metonym of freedom, both in the gardens already noted and the wilderness. O'Keefe delights in the 'wild expanses' of New Mexico and 'she forged a

\footnotetext{
${ }^{5}$ Rita Felski, Hooked: Art and Attachment (Chicago: University of Chicago Press, 2020), pp.xi-xiii.
} 
passage to a world of openness and freedom' (59). Hockney's mature Yorkshire paintings engage 'the living aspect of the landscape' (38). The remarkable late paintings of Sargy Mann use a lightbox or room with an open balustrade as a juxtaposition of in and out, a celebration of light and space, and an invitation to share. For this painter, his portrayed world opened up rather than closed in on losing his sight. Laing writes movingly of our unwillingness to share space in her 'The Abandoned Person's Tale' and her reflections around John Berger's invocation to share 'with hospitality'(105). It is no coincidence that she opens her piece on O'Keefe with an essential painting of the artist's house with an open doorway (58). Laing extends her own hand through her writing and, with another Jamesian flourish, gestures to a shared bench: 'Sit down, you look tired...you're always welcome beside me' (107).

This polyphonic collection of readings interweaves the voices of artists and non-human actors. Laing frequently allows her artists to speak for themselves, often giving them the last word as an act of ventriloquism. For Basquiat: 'freedom might be a possibility yeah, boom, for real' (19); for Agnes Martin: 'beauty is unattached, it's inspirational - it's inspiration' (31); and for Sarah Lucas 'So maybe they saw freedom for what it was, whereas I thought it was somewhere else' (161). At times it is Laing's own voice which completes the piece offering a challenge or a glimpse of an alternate constellation. In an interpretation of the artists' voice, she presses these ideas. For Philip Guston, 'the only reason to be an artist [is] to escape, to bear witness to this'. In Laing's vocalisation, 'He didn't mean escape as in run away from reality. He meant act. He meant unspring the trap. He meant cut through the wire' (122). This sense of freedom and challenge - of the ability to take from the world without damage or cost, to communicate and make fertile abundance with these elements is an irrepressible theme bubbling through Laing's writings. It is one of the powerful ways in which she and her beloved artists alchemise the raw ingredients of suffering, violence and marginalised voices to offer a different and potentially hopeful view of the world. A reparative reading indeed. 